\title{
Wear behavior of GTA coated FeCrC based bond alloy on an AISI 1040 steel substrate
}

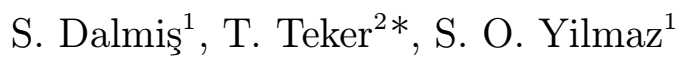 \\ ${ }^{1}$ University of Namık Kemal, Faculty of Engineering, Department of Machine Engineering, \\ 59500, Çorlu-Tekirdă̆, Turkey \\ ${ }^{2}$ University of Adiyaman, Faculty of Engineering, Department of Metallurgy and Materials Engineering, \\ 02040, Adryaman, Turkey
}

Received 15 December 2017, received in revised form 1 August 2018, accepted 5 September 2018

\begin{abstract}
Powders of FeCrC alloy were used for cladding on AISI 1040 plain steel base metal by using gas tungsten arc (GTA) processing. Microstructures of clad layers were examined by an X-ray energy dispersive spectrometer (EDS), scanning electron microscopy (SEM), X-ray diffraction (XRD) and microhardness test. The obtained results indicated that there was a similar microstructure in the all clad layers. The adhesion of the clad layers to the base metal was very good. The microstructures of the clad layers were quite dense. Hypoeutectic or hypereutectic microstructures of the cladded surfaces depend on the powder type and processing parameters. Martensite, austenite $(\gamma)$ and eutectic $\mathrm{M}_{7} \mathrm{C}_{3}$ carbides were obtained at interface zone. The wear tests of the cladded surfaces were performed under dry sliding conditions. It was determined that the pearlitic/bainitic matrix had a lower wear resistance than the primary austenitic matrix.
\end{abstract}

Ke y w or d s: GTA, clad layer, dry sliding wear

\section{Introduction}

High Cr alloys are used for surfaces exposed to high wear rates as hard cladding materials. They have been used in applications including the cement production, mining \& mineral processing, and paper manufacturing industries. Previous research on Fe-Cr-C alloys manufactured with conventional methods has shown that in relation to the alloy composition, $\alpha$ ferrite and complex carbides, such as $\mathrm{M}_{3} \mathrm{C}, \mathrm{M}_{7} \mathrm{C}_{3}$ and $\mathrm{M}_{23} \mathrm{C}_{6}$ are formed in the microstructure. In some studies, carbide forming elements and $\mathrm{Si}$ are added to the structure to modify the carbides type and shape. The structure of the primary $\mathrm{M}_{7} \mathrm{C}_{3}$ carbides surrounded by $\mathrm{M}_{3} \mathrm{C}$ and $\mathrm{M}_{7} \mathrm{C}_{3}$ carbides can be seen in a ledeburitic matrix $\left(\gamma\right.$ and $\left.\mathrm{M}_{3} \mathrm{C}\right)$. Also, in the microstructure, the $\mathrm{M}_{7} \mathrm{C}_{3}$ primary carbides formed at higher $\mathrm{C}$ concentrations when the formation of austenite $(\gamma)$ occurred at lower $\mathrm{C}$ concentrations. The microstructures having $\mathrm{M}_{7} \mathrm{C}_{3}$ primary carbides at higher $\mathrm{C}$ concentrations have a good wear resistance [1-5].
A thin clad layer can be obtained by using GTA processing. This situation is related to both the melting and the subsequent solidification rate simultaneously so that it is possible to obtain quite dense and metallurgically well-bonded clad layer on the base metal. Moreover, the cladded surface with the GTA processing has the potential to produce a fine microstructure with high hardness and wear resistance to be synthesized on a variety of conventional base metals. The microhardness of Fe-Cr-C alloy microstructures depends on fine-grained nonequilibrium $\gamma$-phase in the primary dendrites and the formation of hard $\mathrm{M}_{7} \mathrm{C}_{3}(\mathrm{M}=\mathrm{Cr}, \mathrm{Fe})$ carbides [68].

Wear is an undesirable loss of mass from the surface of the mechanical components. Surface engineering technology is one of the most effective approaches to improve the tribological performance of such components. HVOF spray, thermal burst spray, gas tungsten arc welding, plasma spray, electrodeposition and many other surface engineering techniques are used to 
Table 1. Chemical concentration of the powders used in coating (wt.\%)

\begin{tabular}{lccccccc}
\hline Alloy & Fe & Cr & Si & S & C & P \\
\hline FeCrC & Bal. & 64 & 1.5 & 0.02 & 6.2 & 0.03 \\
\hline
\end{tabular}

Table 2. The geometrical and process parameters of FeCrC composite coatings used in experiments

\begin{tabular}{|c|c|c|c|c|c|c|}
\hline $\begin{array}{l}\text { Welding current }(\mathrm{A}) \\
\text { Traverse speed }\left(\mathrm{mm} \mathrm{min}^{-1}\right) \\
\text { Shielding gas flow rate }\left(\mathrm{l} \mathrm{min}^{-1}\right)\end{array}$ & $\begin{array}{c}100 \\
60 \\
14\end{array}$ & $\begin{array}{c}110 \\
60 \\
14\end{array}$ & $\begin{array}{c}120 \\
60 \\
14\end{array}$ & $\begin{array}{c}130 \\
60 \\
14\end{array}$ & $\begin{array}{c}140 \\
60 \\
14\end{array}$ & $\begin{array}{c}150 \\
60 \\
14\end{array}$ \\
\hline Powder and dimensions & \multicolumn{6}{|c|}{$\mathrm{FeCrC}(25-50 \mu \mathrm{m})$} \\
\hline Sample No & S11 & S12 & $\mathrm{S} 13$ & S14 & $\mathrm{S} 15$ & S16 \\
\hline Widths of cladded surface (mm) & 5 & 5.2 & 5.4 & 5.7 & 6 & 6.2 \\
\hline Penetration depths (mm) & 1.7 & 1.9 & 2.4 & 2.6 & 2.9 & 3.2 \\
\hline Powder and dimensions & \multicolumn{6}{|c|}{$\mathrm{FeCrC}(50-75 \mu \mathrm{m})$} \\
\hline Sample No & $\mathrm{S} 21$ & $\mathrm{~S} 22$ & $\mathrm{~S} 23$ & $\mathrm{~S} 24$ & $\mathrm{~S} 25$ & $\mathrm{~S} 26$ \\
\hline Widths of cladded surface (mm) & 5 & 5.4 & 5.8 & 6 & 6.1 & 6.2 \\
\hline Penetration depths $(\mathrm{mm})$ & 1.5 & 1.8 & 2 & 2.4 & 2.6 & 2.8 \\
\hline Powder and dimensions & \multicolumn{6}{|c|}{$\mathrm{FeCrC}(75-100 \mu \mathrm{m})$} \\
\hline Sample No & S31 & S32 & S33 & $\mathrm{S} 34$ & S35 & S36 \\
\hline Widths of cladded surface (mm) & 5 & 5.3 & 5.7 & 6 & 6.2 & 6.5 \\
\hline Penetration depths $(\mathrm{mm})$ & 1.9 & 2.1 & 2.4 & 2.7 & 2.8 & 3 \\
\hline
\end{tabular}

develop the wear resistance of the plain carbon steel $[9,10]$.

This study systematically investigated the solidification mechanisms, phase transformations, cladded microstructures of more cheap and pure elemental powder mixtures Fe-Cr-C alloy by using GTA processing.

\section{Experimental procedures}

AISI 1040 steel having a size of $100 \times 30 \times 10 \mathrm{~mm}^{3}$ was utilized as base metal in the GTA processing. Chemical compositions of the FeCrC powders having $75-150 \mu \mathrm{m}$ size are given in Table 1 . The operating principle of GTA (Lincoln Invertec V205-T AC/DC) welding systems is schematically shown in Figs. 1a,b. Welding device can make single axle, $300 \mathrm{~mm}$ constant advance motion in both directions. Speed control of the motor system is provided by an inverter. Before using GTA cladding method, surfaces of AISI 1040 steel substrates were cleaned with acetone and then dried. The coating powders were mixed with the binder and plastered to the channels with a width of $4 \mathrm{~mm}$ and depth of $1 \mathrm{~mm}$. The samples were dried for $30 \mathrm{~min}$ at $50^{\circ} \mathrm{C}$ for drying of the binder. The coatings were manufactured by using different welding currents $(110,120,130,140$ and $150 \mathrm{~A})$ at a constant shielding gas flow rate $\left(14 \mathrm{l} \mathrm{min}^{-1}-\mathrm{Ar}\right)$ and traverse speed $\left(60 \mathrm{~mm} \mathrm{~min}^{-1}\right)$. The geometrical characters and pro-
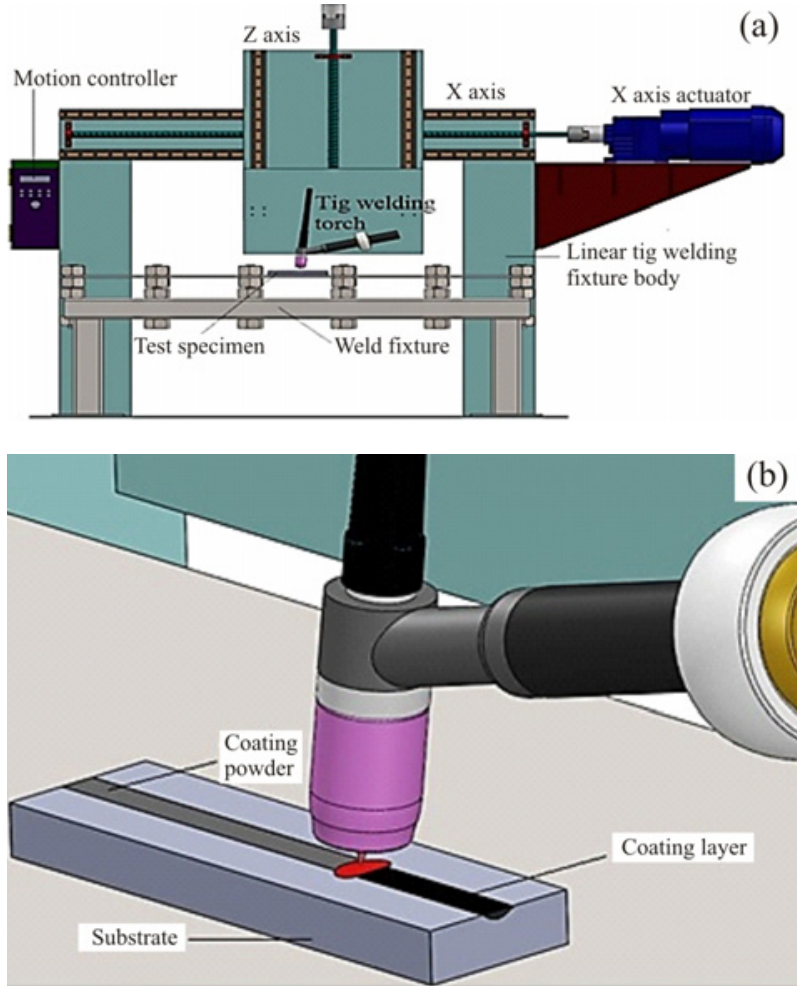

Fig. 1. The operating principle of GTA welding systems.

cess parameters of $\mathrm{FeCrC}$ composite coatings used in experiments are listed in Table 2. 


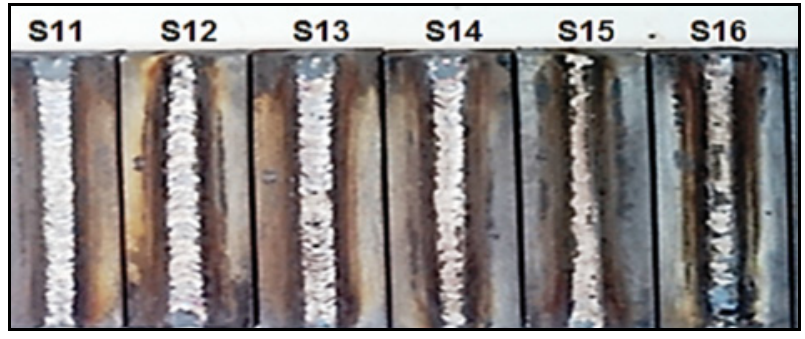

Fig. 2. Macrographs of $\mathrm{FeCrC}$ based composite coatings.

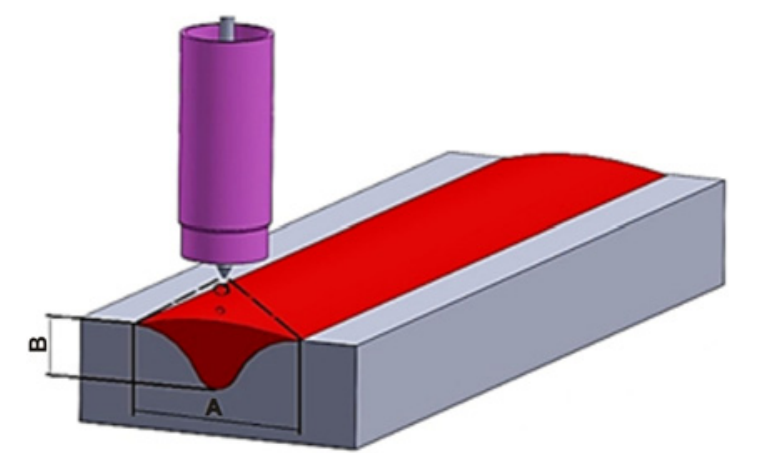

Fig. 3. Coating dimensions obtained in experiments; A is coating length, and B is coating depth.

The samples were prepared by grinding, polishing and etched with a solution having 2 wt. $\% \mathrm{NHO}_{3}+98$ wt.\% ethanol. The surface and cross-sectional morphologies of samples were observed by SEM (Model JEOL JSM-7001F, Japan). Elemental analysis of the clad layer was examined by energy dispersive spectrometer (EDS). The phase and compounds of the cladded surfaces were confirmed by X-ray diffraction (Bruker D8 advance X-ray diffractometer at $40 \mathrm{kV}$, $30 \mathrm{~mA}$ and $\mathrm{Cu} \mathrm{K} \alpha$ radiation source). The microhardness test analysis was used to determine the depth of the clad layers. It was performed with $\mathrm{HV}$ hardness scale under $100 \mathrm{~g}$ loads at $0.5 \mu \mathrm{m}$ intervals by QNESS Q10 test device. The abrasive wear tests of coated samples were performed in the sliding distance of $500 \mathrm{~m}$ at three different loads $(10,20$ and $30 \mathrm{~N})$ using a pin-on-disc type apparatus at room temperature. Abrasive sandpaper material of 120 mesh was used as the counter material. The test specimens were prepared in dimensions of $10 \times 10 \times 10 \mathrm{~mm}^{3}$. The weight losses of samples were recorded by electronic balance with a resolution of $10^{-4} \mathrm{mg}$. Before and after wear tests, wear losses were determined.

\section{Results and discussion}

\subsection{Macro- and microstructure examination of coatings}

Macrographs of FeCrC based composite clad layers
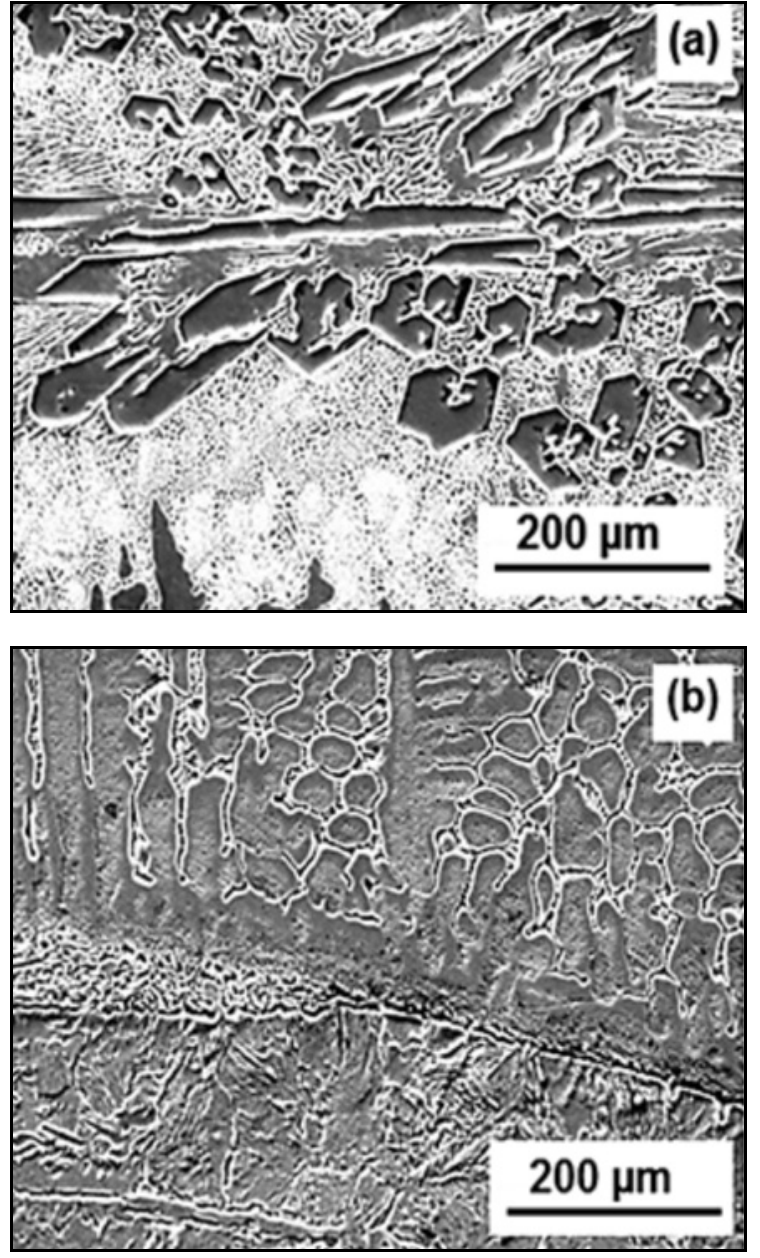

Fig. 4. SEM micrographs of FeCrC based S1 composite coating: (a) coating layer and (b) transition zone.

are given in Fig. 2. The cladding dimensions obtained from experiments are shown in Fig. 3. The geometrical characters of $\mathrm{FeCrC}$ composite coatings used in experiments are given in Table 2. Figures 4-7 present the SEM micrographs of FeCrC based composite clad layers. Three zones, being clad layer, HAZ and base metal, are identified on the cladded surfaces. As a result of the microstructural examinations, it has been determined that the main phase is face-centered cubic (fcc) austenite $(\gamma)$ in case of the minor phase's being $\mathrm{M}_{7} \mathrm{C}_{3}(\mathrm{M}=\mathrm{Cr}, \mathrm{Fe})$ carbide. The findings acquired are completely consistent with the typical concentrations of $\mathrm{Fe}, \mathrm{C}$ and $\mathrm{Cr}$ in alloys generating austenite and $\mathrm{M}_{7} \mathrm{C}_{3}$ phases. The phases acquired in the GTA processed FeCrC clad layers are significant due to the similarity of the solidification mechanisms of the ternary Fe-Cr-C alloy system to the presented ones [11]. In case of the combination of comparatively high powder densities and particular energies with adequately low powder feed rates, melting of the base metal and the hypoeutectic formation are supported. Therefore, the 
Ta b le 3. EDS analyses findings of S1 sample

\begin{tabular}{|c|c|c|c|c|}
\hline \multirow{2}{*}{ Sample No } & \multirow{2}{*}{ Analyses points } & \multicolumn{3}{|c|}{ EDS analyses (at.\%) } \\
\hline & & $\mathrm{Fe}$ & $\mathrm{Cr}$ & $\mathrm{C}$ \\
\hline \multirow[t]{4}{*}{$\mathrm{S} 1$ (a) } & 1. point & 79.41 & 11.16 & 9.43 \\
\hline & 2. point & 64.14 & 7.35 & 28.51 \\
\hline & 3. point & 58.67 & 1.50 & 39.84 \\
\hline & 4. point & 67.39 & 0.63 & 31.98 \\
\hline \multirow[t]{2}{*}{$\mathrm{S} 1$ (b) } & 1. point & 56.45 & 18.40 & 25.16 \\
\hline & 2. point & 69.19 & 7.70 & 23.11 \\
\hline
\end{tabular}

Ta ble 4. EDS analyses findings of S5 sample

\begin{tabular}{llrrrr}
\hline \multirow{3}{*}{ Sample No } & Analyses points & \multicolumn{4}{c}{ EDS analyses (at.\%) } \\
\cline { 3 - 6 } & & $\mathrm{Fe}$ & $\mathrm{Cr}$ & $\mathrm{C}$ & $\mathrm{Si}$ \\
\hline \multirow{2}{*}{ S5 (a) } & 1. point & 65.97 & 12.04 & 19.26 & 2.72 \\
& 2. point & 61.41 & 10.61 & 24.80 & 3.18 \\
& 3. point & 62.48 & 3.00 & 33.57 & 0.95 \\
\hline \multirow{2}{*}{ S5 (b) } & 1. point & 65.73 & 11.14 & 21.21 & 1.92 \\
& 2. point & 58.05 & 12.09 & 27.85 & 2.00 \\
\hline
\end{tabular}
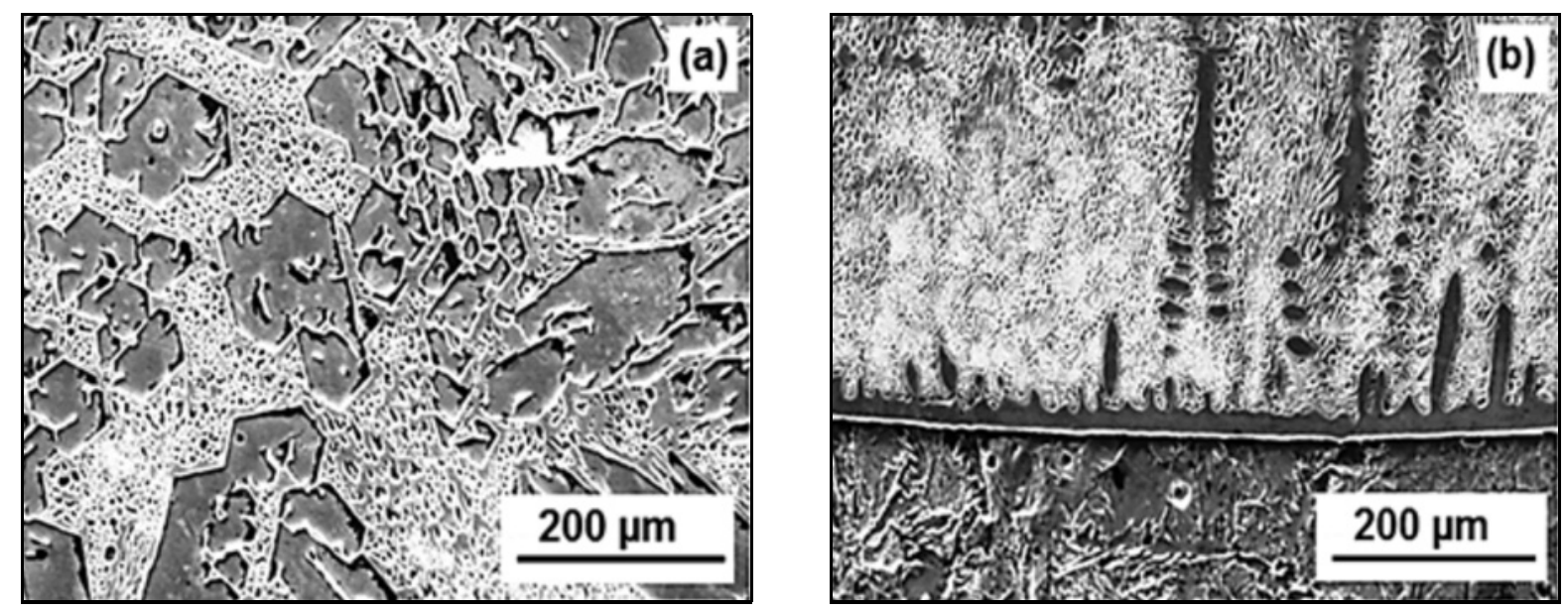

Fig. 5. SEM micrographs of FeCrC based S2 composite coating: (a) coating layer and (b) transition zone.

chemical composition is changed. Nevertheless, the decreased specific energy and powder densities and the increased rate of powder feed determine the melting of the base metal and the emergence of hypereutectic microstructures. Lower specific energies and rapid solidification rates are caused by higher process rates, as a result of which microstructural grain refinement at the thickness of clad layer occurs. Chemical distribution is influenced by the volume of molten pool and base metal. Therefore, the presence of hypoeutectic or hypereutectic microstructures influencing crystal structures in the microstructure of clad layers depends on the processing parameters, which have an effect on the relative amounts of the molten metal from the base metal and the clad layers. Basically, the absorption of the heat input provided by the electrode takes place in the alloy powder mixture. Therefore, the level of substrate melting is decreased which ensures weak adhesion force between clad layer and base metal. In comparison with the findings of S1-S6 with comparatively high powder densities, finer hypoeutectic microstructures are obtained as a result of the increase in the process speed rate. Figure 8 presents the findings of the XRD analyses of base metal and the clad layer of sample S6. It is indicated that mainly $\mathrm{FeCrC}$, $\mathrm{Cr}_{7} \mathrm{C}_{3}, \mathrm{CrFe}_{4}$ constitute the clad layer. 

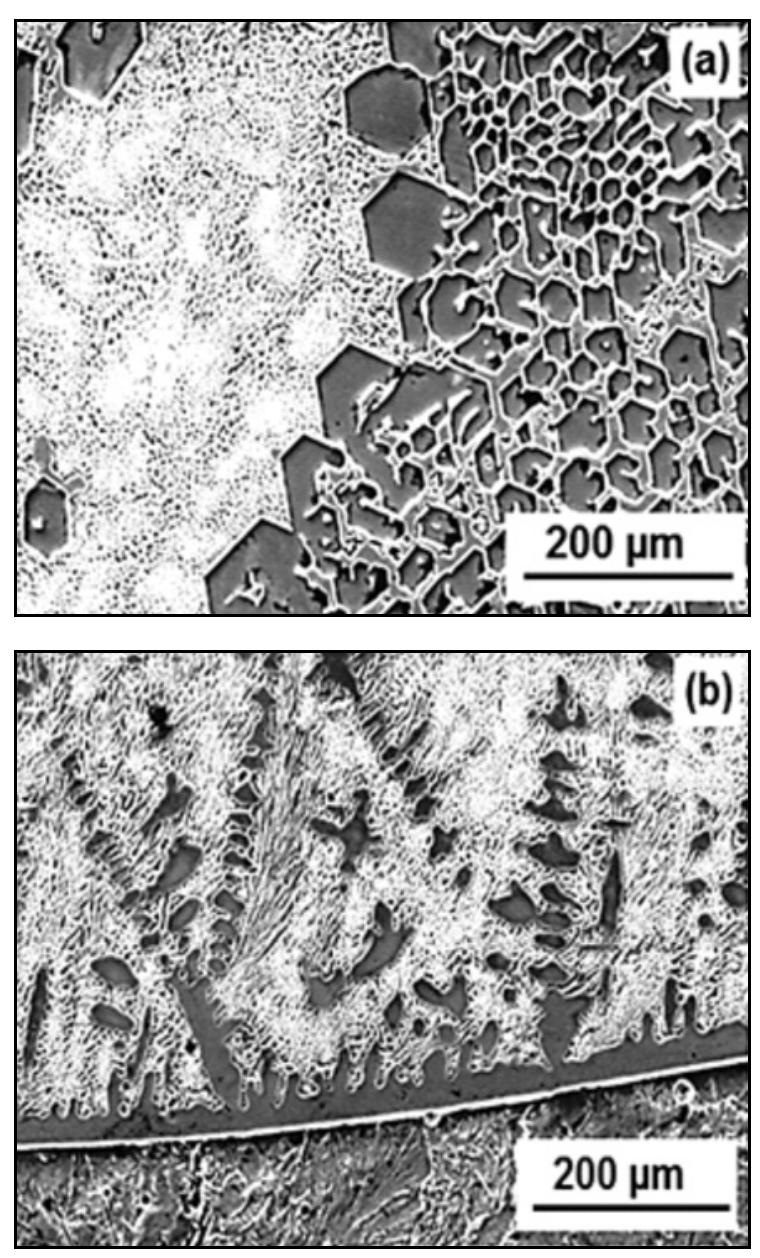

Fig. 6. SEM micrographs of $\mathrm{FeCrC}$ based $\mathrm{S} 4$ composite coating: (a) coating layer and (b) transition zone.

Many reasons for the formation of austenitic $(\gamma)$ phase between the eutectic and primary dendrites may be discussed in the microstructure. The reasons mentioned above are as follows: the decreased martensitestart temperature (Ms), the increased concentration of austenite stabilizing elements in the clad layer and cooling rates. In the $\mathrm{Fe}-\mathrm{Cr}-\mathrm{C}$ equilibrium phase diagrams, it is indicated that in accordance with the alloy composition, $\mathrm{M}_{7} \mathrm{C}_{3}(\mathrm{M}=\mathrm{Cr}, \mathrm{Fe})$ or $\mathrm{M}_{3} \mathrm{C}(\mathrm{M}=\mathrm{Fe}, \mathrm{Cr})$ carbides or austenite ( $\gamma$-primary dendrite) can constitute the primary phase below the liquid temperature of $\mathrm{Fe}, \mathrm{Cr}$ alloys in a higher carbon concentration.

Figures 9 and 10 present the EDS analysis results of FeCrC based S1 and S5 composite coatings (Table 3 and 4). The findings acquired for the chemical concentrations of alloying elements for various areas indicate the presence of two different types of structures. While in accordance with the hypoeutectic structure, interdendritic eutectic and the primary dendrite were meant, in accordance with the hypereutectic structure the inter carbide eutectic microstructure and the primary carbide were meant. It is noted that the size and
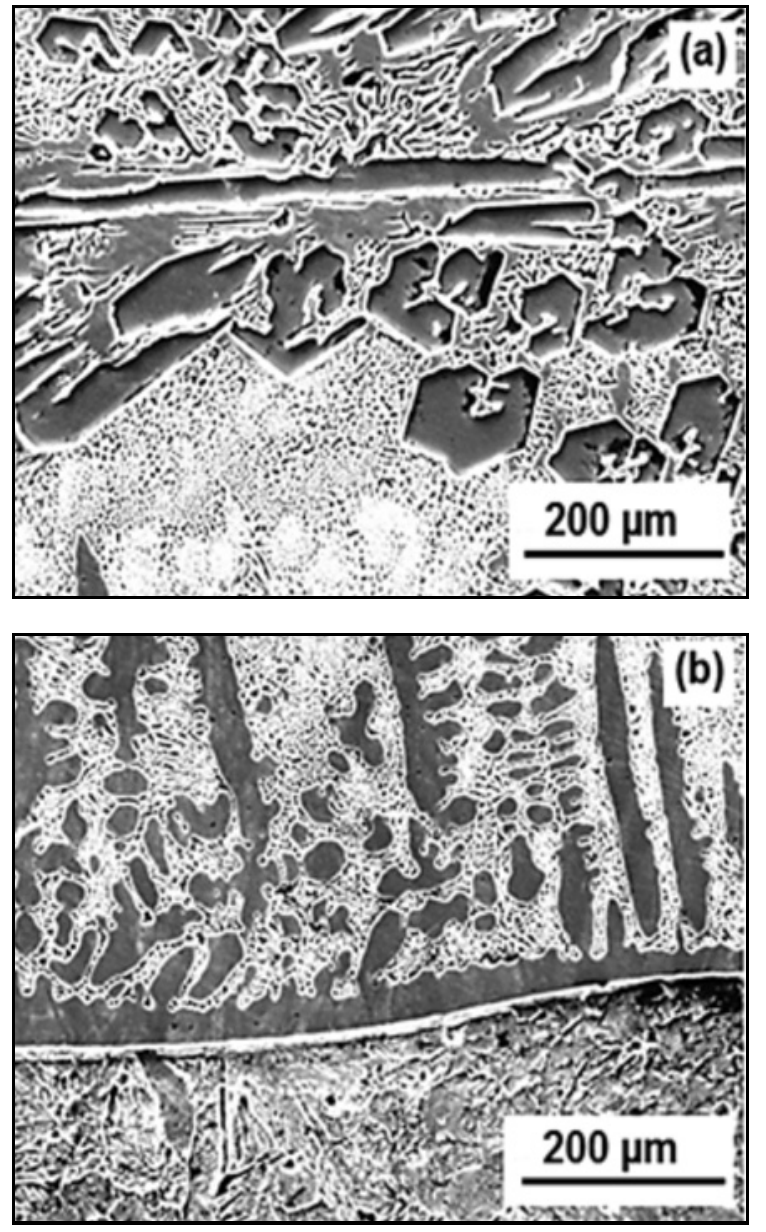

Fig. 7. SEM micrographs of FeCrC based S5 composite coating: (a) coating layer and (b) transition zone.

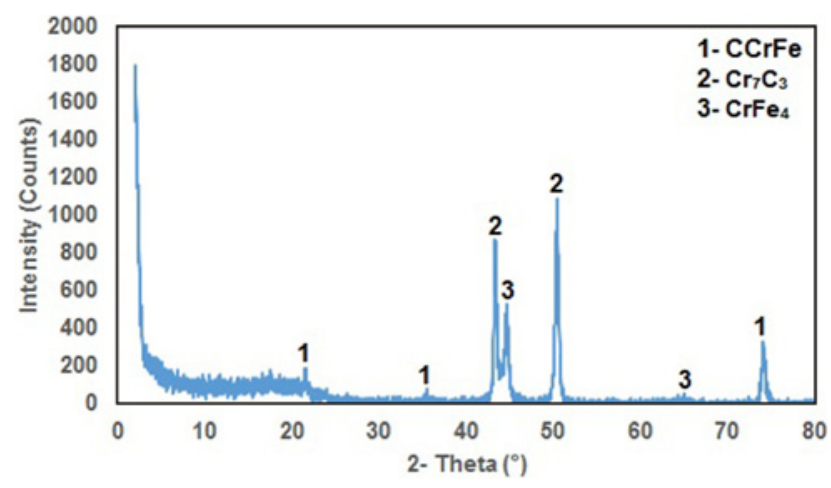

Fig. 8. X-ray diffraction for S6 sample.

spacing of the phases between the eutectic and dendrite microstructures associate the solidification rate and the thermal gradient in the molten pool perpendicular to the solid/liquid interface. Furthermore, it is possible to generate the structures of the refined dendritic at comparatively low or medium thermal gradients at higher solidification rates. The finding acquired indicates the emergence of two basic structures 

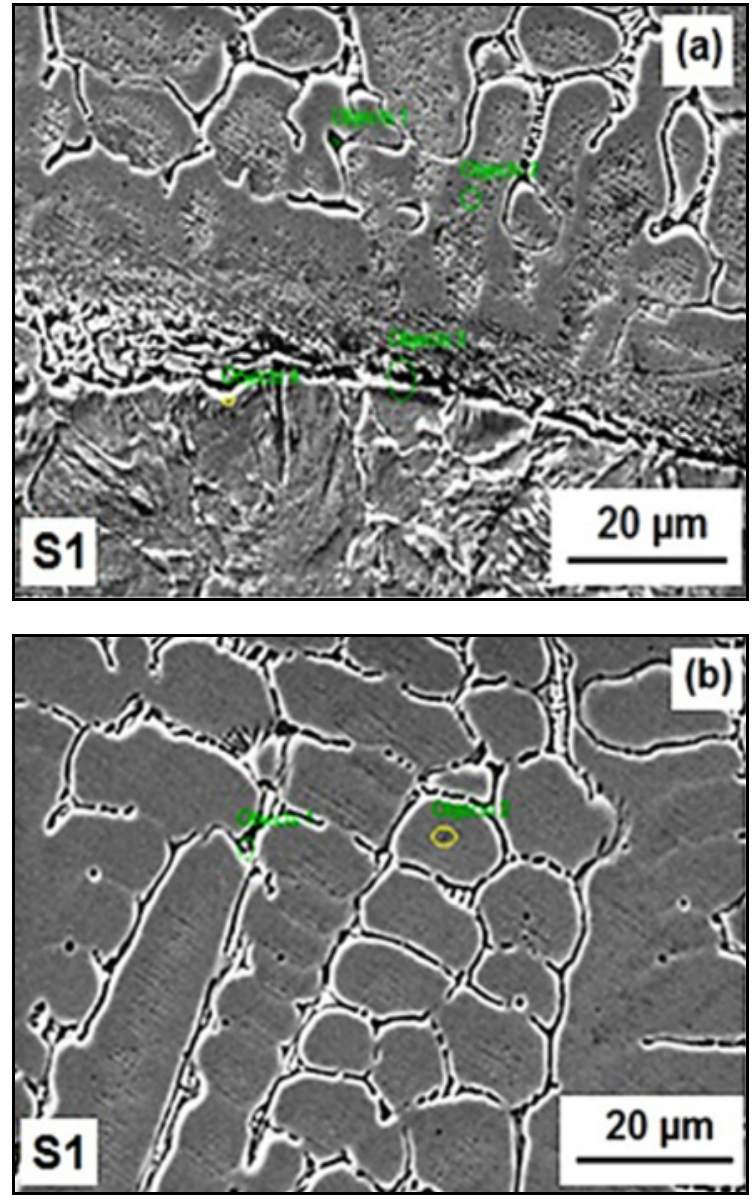

Fig. 9. EDS analyses findings of $\mathrm{FeCrC}$ based $\mathrm{S} 1$ composite coating: (a) coating layer and (b) transition zone.

in accordance with the parameters of the GTA processing, and the alloy compositions determine it. The emergence of $\mathrm{M}_{7} \mathrm{C}_{3}$ primary carbides and eutectic of austenite and $\mathrm{M}_{7} \mathrm{C}_{3}$ carbides is included in the second structure mechanism. The first structure includes the emergence of primary dendrites of fcc eutectic and austenite and hcp $\mathrm{M}_{7} \mathrm{C}_{3}(\mathrm{M}=\mathrm{Cr}, \mathrm{Fe})$ carbides.

The melting of the base metal, chemical composition and the emergence of hypoeutectic microstructures are significantly affected by the high powder densities and certain energies with adequately low rates of powder feed. Nevertheless, when the increased rate of solidification decreases the base metal melting, the emergence of hypereutectic microstructures is ensured. Microstructure grain refinement at the clad layer is ensured by a higher rate of the solidification. The chemical distribution of alloying elements is affected by alloy powder and base metal of the chemical composition. Therefore, hypoeutectic or hypereutectic microstructures created by crystal structures in the clad layer are formed by the processing parameters that influence the relative amounts of the molten material from the base metal and the coating.
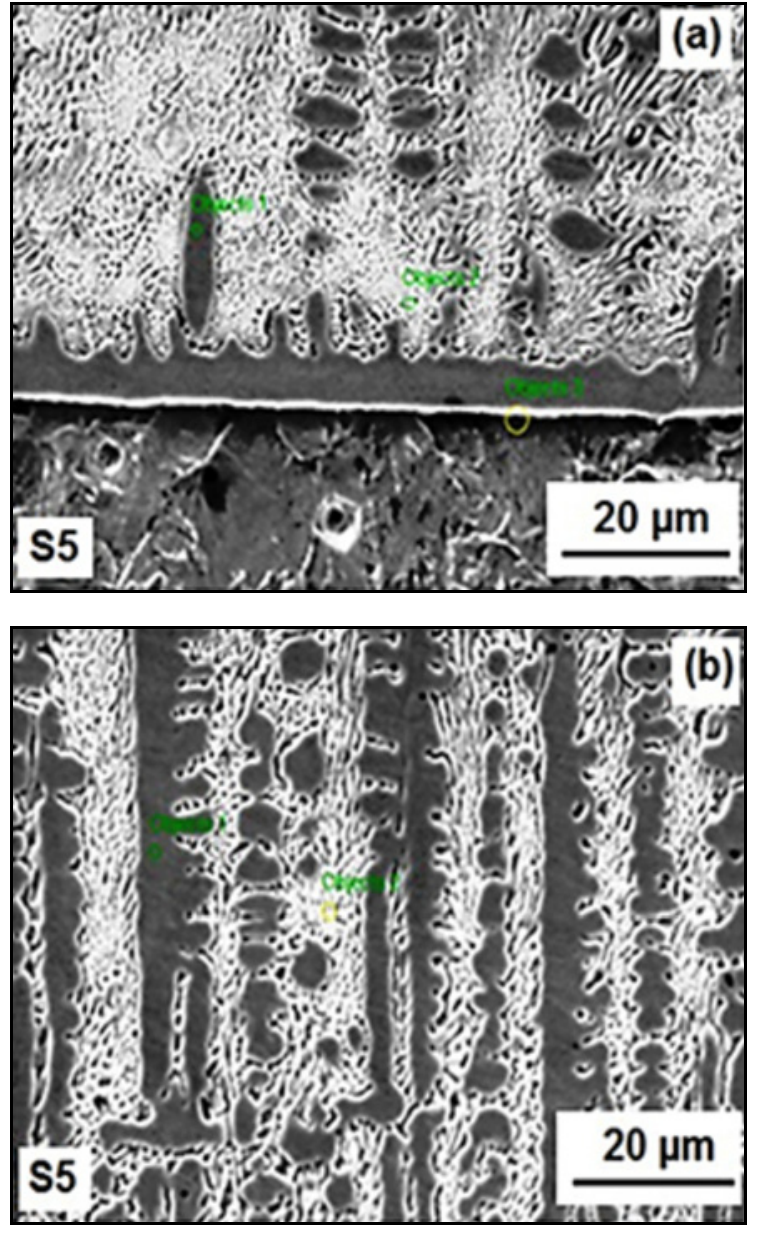

Fig. 10. EDS analyses findings of $\mathrm{FeCrC}$ based S5 composite coating: (a) coating layer and (b) transition zone.

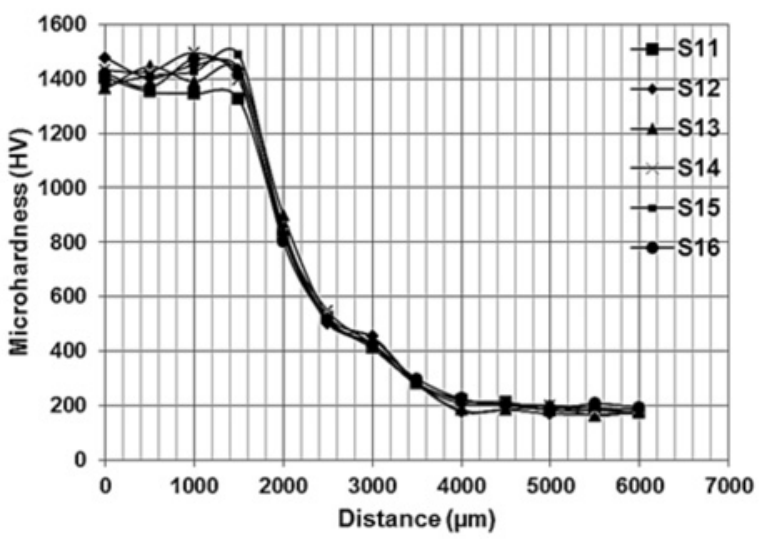

Fig. 11. Microhardness curves of FeCrC based S11-S16 composite coatings.

\subsection{Microhardness test}

Changes of microhardness in the cross-section of the clad layers are given in Figs. 11-13. The hardness of clad layer changes values between 200 and 


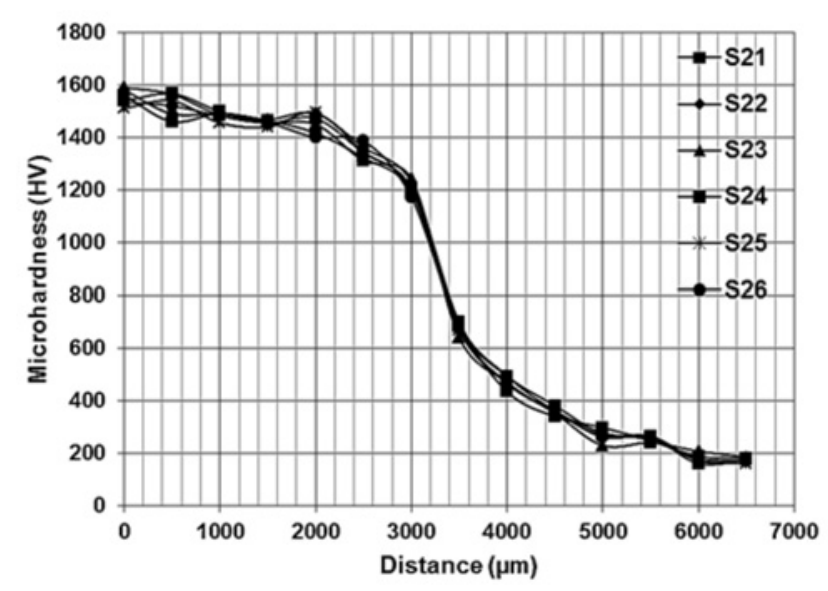

Fig. 12. Microhardness curves of FeCrC based S21-S26 composite coatings.

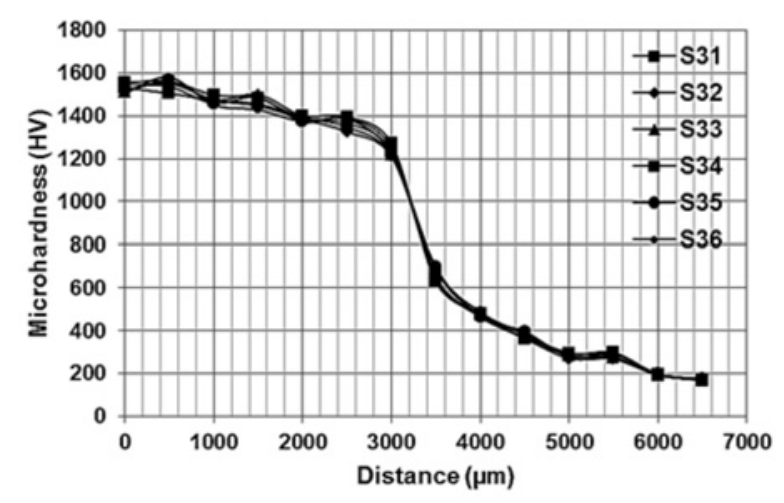

Fig. 13. Microhardness curves of FeCrC based S31-S36 composite coatings.

$1550 \mathrm{HV}$, according to process parameters and the concentration of cladding powder. The hardness results are examined. The increase in the heat input leads to melting of the AISI 1040 steel base metal and increases total thickness and width of the clad layer, but it reduces average hardness values. The hardness profiles show that the significant surface hardening is performed by the GTA processing. The microhardness values change from $900 \mathrm{HV}$ to base metal hardness value of $200 \mathrm{HV}$. The variations between 300 $1500 \mathrm{HV}$ are caused by the presence of large carbides, which is associated with the structure of the composite material. Deep exchange of the clad layer hardness in the case of low processing speed refers to coarsening of the microstructure produced, as shown in Fig. 11. On the contrary, the hardness profile of the refined S5 microstructure obtained at a much higher processing speed shows less variability. The relatively stepped gradients of the hardness profiles in the interface region indicate the presence of the narrow heat-affected zone, which is a natural feature of GTA surface hard facing. Formations of hard $\mathrm{M}_{7} \mathrm{C}_{3}$ carbides in both the
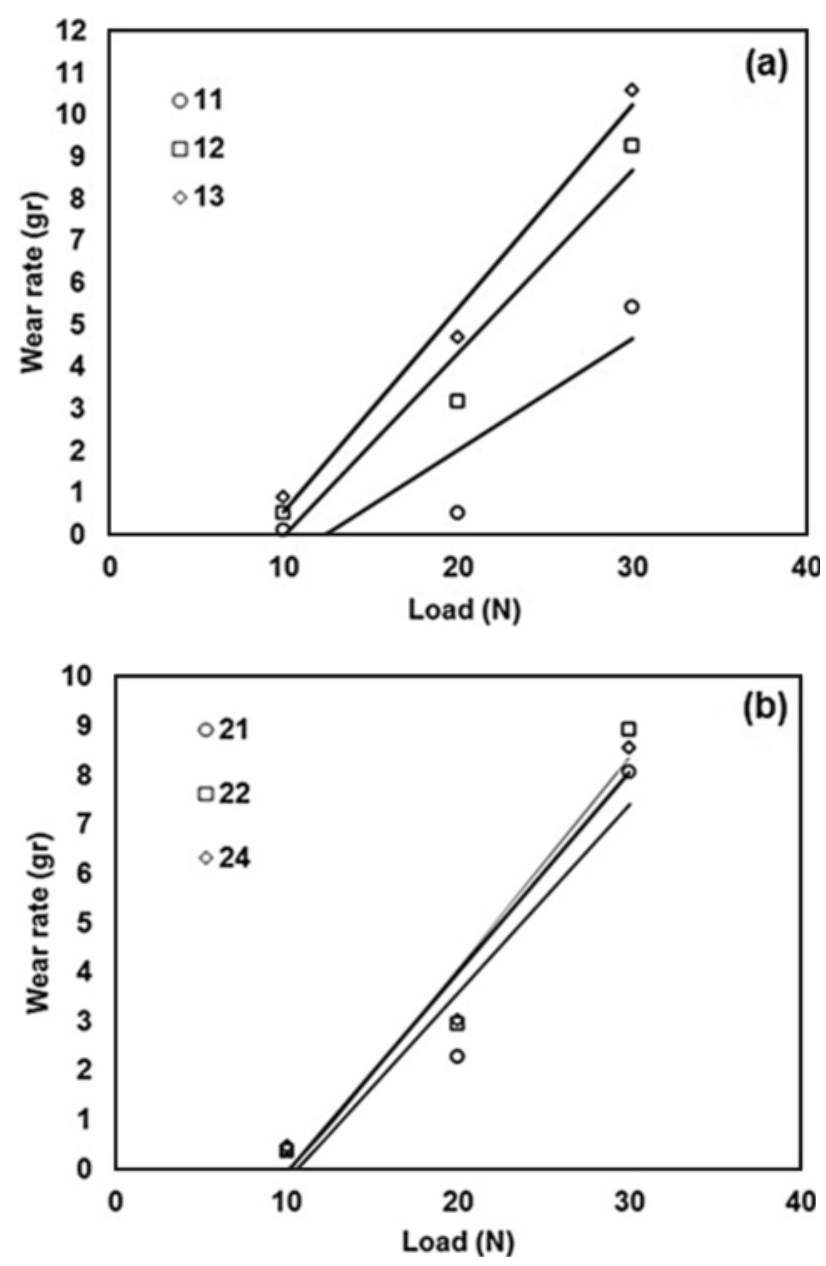

Fig. 14. The wear rates of the low alloy AISI1040 coated with $\mathrm{FeCrC}$ alloy powders.

primary phase and the eutectic lead to the higher hardness of the hypereutectic microstructures. Presence of austenite phase in the primary dendrites has an important effect on the lower hardness of the hypoeutectic.

The higher hardness values in the cladded surface are in association with the increase in the Cr content which supports the martensite structure. In principle, at relatively high powder feed rates, the energy delivered with the electrode, the heat input absorbed with the alloy powder mixture, and this reduced the extent of melting of base metal, resulting in poor adhesion at the interface of the cladding/base metal.

Because ferrite $(\alpha)$, austenite $(\gamma)$ and $\mathrm{M}_{3} \mathrm{C}$ carbides are much softer than $\mathrm{M}_{7} \mathrm{C}_{3}$ carbides [11-15], the cladding of GTA processing brings higher hardness values than by conventional methods. Distributions of the hard carbides are uniform in both the primary phase and the austenite $(\gamma)$ phase. The hardness of the cladding is associated with both the crystal structure type and the grain size which are influenced by the GTA processing parameters. 


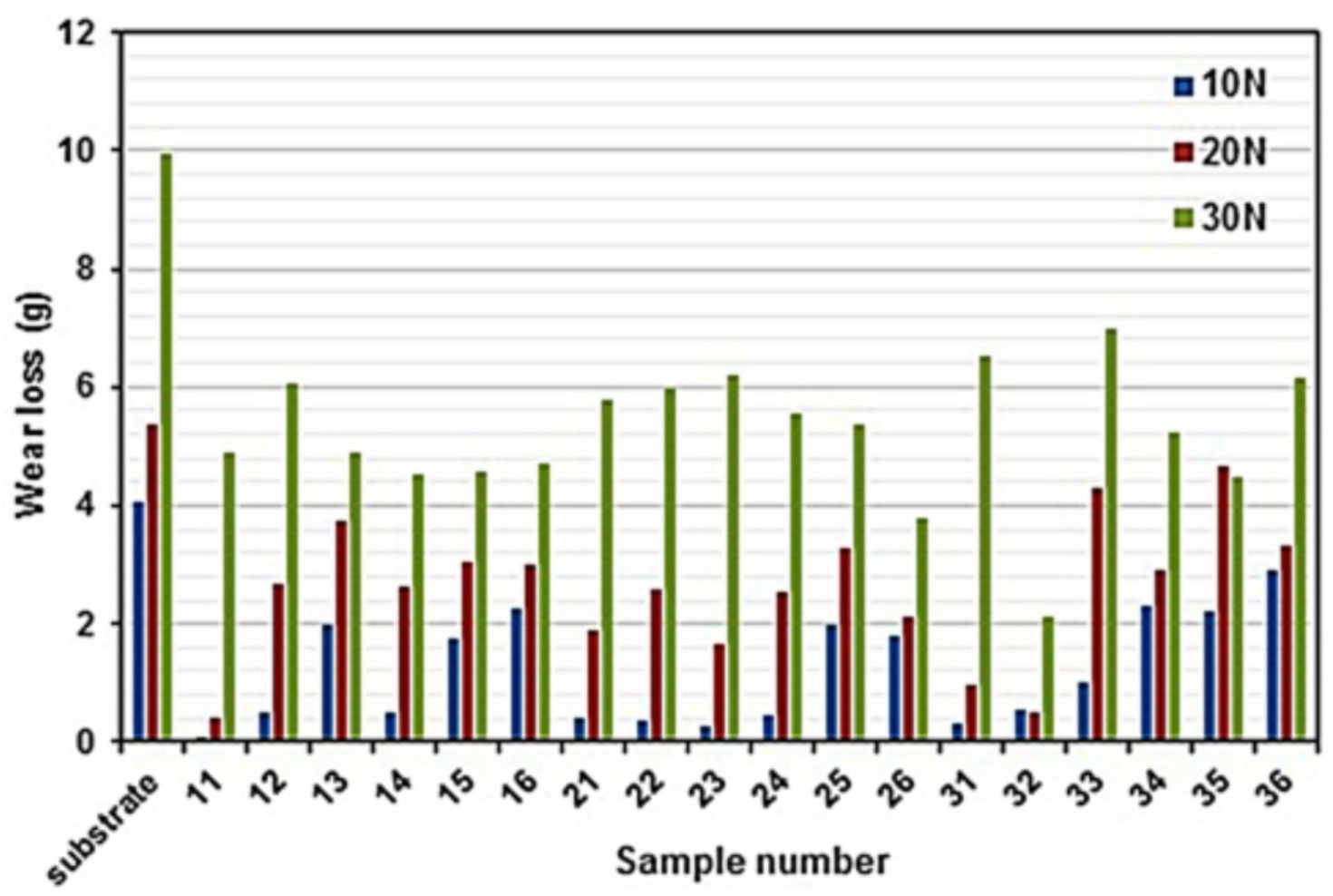

Fig. 15. The comparison of wear test results of the low alloy AISI1040 coated with FeCrC alloy powders.

\subsection{Wear test}

The wear rates of the AISI 1040 steel are given in Figs. $14 \mathrm{a}-\mathrm{c}$ at room temperature. Figure 15 shows a comparison of wear test results of the low alloy AISI1040 coated with FeCrC alloy powders. Chemical composition, uniform distribution of hard carbides, grain size and type of solidified phases play an important role on the mechanical and tribological properties of the clad layer. As seen from the figure, the increase in eutectic temperature decreased weight loss. Also, the large proeutectic carbides in the hypereutectic samples react differently than the eutectic carbides to the abrasive environment. Smaller proeutectic carbides are tougher than the eutectic carbides [1214]. As a result, it was considered that due to the increase of eutectic temperature, the effectiveness of proeutectic carbides in the hypereutectic samples decreased weight loss during wear tests. Moreover, during abrasive wear, the type of the matrix is also important. Microstructural investigations have shown that the cladded surfaces of the hypoeutectic samples have a pearlitic/bainitic combination, on the other hand, samples having the hypereutectic matrix are primarily austenite. As matrix, the phase of austenite has two important effects; the first one is the alloys having been reinforced with soft matrix and hard carbides occupy an important place among wear resistance materials, since it is possible to take advantage of both the energy absorption properties of the soft phase and the wear resistance of the carbides forming in the soft phase. The second one is: austenite is a soft phase, but it transforms into martensite under the load during wear. This statement can be observed in Fig. 14, in which the X-ray diffraction data contained follow the change in phases on the wear surface of the abrasion samples from the sample S4. Figure 14a shows the martensite, the presence of austenite and $\mathrm{M}_{7} \mathrm{C}_{3}$ phases. On the other hand, Fig. 14b indicates that the sample does not contain any significant austenite in the abraded surface. As the energy input increases, the cladding area grows and hardness decreases. When the grain size is reduced, FeCrC reinforced samples have decreased hardness and wear rates are increasing.

In this investigation of the wear process activated, the high Cr processed surfaces also contain both fracture and plastic deformation. That is, the wear behavior interacts differently with the orientation of the carbide rods relative to the wear surface of the cladding. In the samples with the carbides oriented transverse to the abrasion direction, and with the long axis of the carbide rods perpendicular to the wear surface, the carbide rods bend and fracture very near the surface (Fig. 14a). In the circumstances, it was understood that the tangential forces exerted by moving wear particles led to bending. Throughout bending, the fracture occurred since tensile stress develops on the backside of carbide rods. When the rods got thicker, bending and fracture under the same loads occurred difficultly (Fig. 14b). Therefore, it is expected that sur- 
faces with high Cr content with low heat input or high hyperactive compositions are more resistant to abrasion because they involve larger carbides. It is understood that the carbide structure of these composite materials is effective on the abrasive tribal environment. Also, the structure of the matrix plays an important role in the performance of carbides. Finally, it is seen from the results of the high Cr cladded surfaces that austenite matrix phase, which has a ductile structure serves as a better supporting environment for $\mathrm{M}_{7} \mathrm{C}_{3}$ carbides than pearlitic/bainitic matrix phases. Through wear test, austenite phase having ductility and strain hardening ability allows carbides to deform around the matrix. Thus, depending on applying a hydrostatic pressure around them, it delays the onset of fracture. Besides, the softer austenite may continue to provide carbides after fracture, which may further reduce the material removal rate.

The hardness of the hypereutectic and hypoeutectic samples is similar, on the other hand as seen from the Figs. 11 and 14 the wear rate of the hypereutectic samples is lower than that of the hypoeutectic samples. This result is thought to be due to the microstructure of the matrix because investigations on high $\mathrm{Cr}$ alloys have shown that austenitic irons show better performance in wear resistance than the martensitic or pearlitic counterparts [13-16]. Furthermore, austenite in high $\mathrm{Cr}$ enriched $\mathrm{Cr}-\mathrm{Fe}-\mathrm{C}$ compositions has some features that are further improving the wear resistance of the austenitic composition under the experimental conditions. It includes these features at room temperature as the strain hardenability, ductility and thermodynamic metastability. In other words, austenite has a more ductile structure, and under the normal and tangential forces applied by abrasive particles, it can flow more easily without fracturing. As shown in Fig. 8, a matrix, which is fracture free, is detected near the wear grooves in the austenite matrix, in other words, the austenitic matrix absorbs more the mechanical energy than pearlitic/bainitic and-or martensitic structures by allowing plastic deformation [17]. For this reason, the plastic deformation adjacent to the grooves of the hypoeutectic structures is higher (Fig. 11a). Also, in the austenitic matrix, two additional strengthening mechanisms can form due to plastic deformation, which increases surface hardness and decreases the wear rate [18]. During the abrasive wear process, with groove formation also some of the mechanical energy is spent for the martensitic transformation. Finally, in the microstructure of the hypereutectic and hypoeutectic samples, different types of the wear mechanisms were observed.

\section{Conclusions}

In this study, FeCrC alloy powders were used to coating on AISI 1040 steel base metal by GTA processing. Conclusions of the study are presented in the following facts:

1. The higher heat input led to larger carbide sizes in the samples. The microstructures of the coated surface have shown that the hypereutectic samples have the coarsest structure depending on the amount of heat input. It was observed that the carbide phase in all regions of the coated surface is mostly of the $\mathrm{M}_{7} \mathrm{C}_{3}$ type, which changes the powders concentration.

2. Primary $\mathrm{M}_{7} \mathrm{C}_{3}$ particles in case of the solidification of a hypereutectic molten pool constitute the first phase that takes place. The flow of liquid metal in the mold cavity can carry the solid $\mathrm{M}_{7} \mathrm{C}_{3}$ particles in question on a freeway due to the high-temperature difference between the primary carbide formation and the eutectic reaction. After the formation of the abovementioned $\mathrm{M}_{7} \mathrm{C}_{3}$ precipitates, it is possible that the decreasing temperature of the casting melt is not sufficient for their complete dissolvement because $(\gamma)$ austenite, $(\alpha)$ ferrite and $\mathrm{M}_{3} \mathrm{C}$ are considerably more ductile compared to $\mathrm{M}_{7} \mathrm{C}_{3}$ carbides.

3. Significantly higher hardness values are demonstrated by the coatings with GTA processing when compared to those acquired by traditional techniques due to the considerably uniform distribution of hard carbides in the primary phase and the eutectic and the presence of the significantly stretched austenite $(\gamma)$ phase.

4. The hypoeutectic microstructures created by the austenite $(\gamma)$ prime dendrites and the interdendritic eutectic consisting of $\mathrm{M}_{7} \mathrm{C}_{3}(\mathrm{M}=\mathrm{Cr}, \mathrm{Fe})$ carbides and austenite were produced in areas having higher solidification.

5. There are lower hardness values in hypoeutectic microstructures because primary dendrites and the low concentration of $\mathrm{Cr}$ and $\mathrm{C}$ have the austenite phase. The reason for this is the fact that the increase in hardness takes place if more $\mathrm{M}_{7} \mathrm{C}_{3}$ carbides are contained in the hypereutectic microstructures in the eutectic, as well as the primary phase.

\section{References}

[1] Matthews, A., Leyland, A., Holmberg, K., Ronkainen, H.: Surface and Coatings Technology, 100, 1998, p. 1. doi:10.1016/S0257-8972(97)00578-1

[2] Xiaolei, W., Guangnan, C.: Materials Science and Engineering A, 270, 1999, p. 183. doi:10.1016/S0921-5093(99)00159-8

[3] Zapponi, M., Quiroga, A., Pérez, T.: Surface and Coatings Technology, 122, 1999, p. 18. doi:10.1016/S0257-8972(99)00403-X

[4] Chen, S. R., Davies, H. A., Rainforth, W. M.: Acta Materialia, 47, 1999, p. 4555. $\underline{\text { doi:10.1016/S1359-6454(99)00334-1 }}$ 
[5] Tsakiris, V., Edmonds, D. V.: Materials Science and Engineering A, 273, 1999, p. 430. doi:10.1016/S0921-5093(99)00322-6

[6] Karaman, I., Sehitoglu, H., Gall, K., Chumlyakov, Y. I., Maier, H. J.: Acta Materialia, 48, 2000, p. 1345. doi:10.1016/S1359-6454(99)00383-3

[7] Teker, T., Karataş, S., Yilmaz, S. O.: Archives of Metallurgy and Materials, 59, 2014, p. 925. doi:10.2478/amm-2014-0156

[8] Modenesi, P. J., Apolinário, E. R., Pereira, I. M.: Journal of Materials Processing Technology, 99, 2000, p. 260. doi:10.1016/S0924-0136(99)00435-5

[9] Davis, J. R.: Handbook of Thermal Spray Technology. Thermal Spray Society Training Committee. Materials Park, ASM International 2004.

[10] Jafari, M., Enayati, M. H., Salehi, M., Nahvi, S. M., Park, C. G.: International Journal of Refractory Metals and Hard Materials, 41, 2013, p. 78. doi:10.1016/j.ijrmhm.2013.02.006
[11] Nurminen, J., Näkki, J., Vuoristo, P.: International Journal of Refractory Metals and Hard Materials, 2, 2009, p. 472. doi:10.1016/j.ijrmhm.2008.10.008

[12] Xie, J., Chen, N., Shen, J., Teng, L., Seetharaman, S.: Acta Materialia, 53, 2005, p. 2727. doi:10.1016/j.actamat.2005.02.039

[13] Liu, A., Guo, M., Hu, H., Li, Z.: Scripta Materialia, 59, 2008, p. 231. doi:10.1016/j.scriptamat.2008.03.012

[14] Liu, X., Gu, Y.: Materials Letters, 60, 2006, p. 577. doi:10.1016/j.matlet.2005.09.041

[15] Liu, X., Wang, H.: Wear, 262, 2007, p. 514. doi:10.1016/j.wear.2006.06.012

[16] Yaz, M., Yilmaz, O., Teker, T., Kovove MaterialyMetallic Materials, 49, 2011, p. 297. doi:10.4149/km-2011-4-297

[17] Zum Gahr, K. H., Doane, D. V.: Metallurgical Transaction A, 11, 1980, p. 613. doi:10.1007/BF02670698

[18] Zum Gahr, K. H., Eldis, G. T.: Wear, 64, 1980, p. 175. doi:10.1016/0043-1648(80)90101-5 